\title{
Effect of Electrical Damping Ratio on Maximum Average Power of an Electromagnetic Vibration Harvester at Resonance and off-Resonance Conditions
}

\author{
Vijay Patil, Mahadev Sakri
}

\begin{abstract}
Energy harvesting has opened up new ways to power low energy electronics without any need for batteries. The most advanced types of harvesters are piezoelectric, electrostatic and electromagnetic which use kinetic energy in form of vibrations. Electromagnetic harvesters (EHs) are efficient, less costly and offer huge design flexibility. As such, in this paper some analytical and experimental studies on maximum average harvestable power (Pave) from typical design of $\mathrm{EH}$ using the popular coupling architecture (a cylindrical magnet oscillating in a copper coil) have been carried out. The effect of frequency of excitation and electrical $\left(\zeta_{e}\right)$ and mechanical damping ratios $\left(\zeta_{m}\right)$ on Pave obtained from an $\mathrm{EH}$ has been investigated. For this purpose, an $\mathrm{EH}$ using NdFeB (neodymium magnet) magnet oscillating in a copper coil has been designed and developed. An experimental test set up has developed which comprises of (i) a cam-follower type drive mechanism to simulate a vibration source with variable amplitude and frequency of base excitation, (ii) a spring-mass system with an $\mathrm{EH}$ system in parallel with the spring to provide the relative motion between the magnet and the copper coil, (iii) the attendant instrumentation comprising of ultrasonic sensor to sense the displacements of base and mass, motor drive speed measurement and an open source platform (ARDUINO) with programmable circuit board and software and data acquisition system. Using the developed experimental set up, (i)frequency response curve for vibrating system with $\mathrm{EH}$ has been obtained from which equivalent electrical damping $\zeta_{e}$ has been determined using half power point method, and (ii)the values of relative displacements of magnet and coil, at various excitation frequencies have been recorded. Using the analytical expression for the Pave of SDOF EH has been determined both at resonance and off resonance conditions, for three different values of $\zeta_{e}$ namely $\zeta_{e}=\zeta_{m}, \zeta_{e}=5 \zeta_{m}$, and $\zeta_{e}=10 \zeta_{m}$. It is observed that the maximum $\boldsymbol{P}_{\text {ave }}$ is obtained for condition $\zeta_{e}=\zeta_{m}$. As the value of $\zeta_{e}$ increases, the $P_{\text {ave }}$ increases, at resonant frequency and considerable power is made available at off-resonance frequencies. It is concluded that $\zeta_{e}$ should be increased to enhance the maximum average harvestable power from $\mathrm{EH}$ and vibrating system should be so designed to have $\zeta_{m}$, as small as possible.
\end{abstract}

Keywords: Vibration based Electromagnetic harvester (VEH), electrical damping ratio $\left(\zeta_{e}\right)$, mechanical damping ratio $\left(\zeta_{m}\right)$, Resistive load $\left(R_{L}\right)$

Revised Manuscript Received on July 22, 2019

Vijay Patil, Mechanical Engineering Department, Annasaheb Dange College of Engineering and Technology, Ashta,Sangli, Maharashtra, 416301 .

Dr.Mahadev Sakri, Mechanical Engineering Department, BLDEAs V.P. Dr. P.G .Halakatti College of Engineering \& Technology, Vijayapur .586101 .

\section{INTRODUCTION}

Electromagnetic Harvester (EH) converts vibration energy in electrical energy. These are also called vibration based EH. The principal advantages of EHs are that they are reliable, easy in manufacturing, and can be made available in sizes even at micro scale. EHs have very low power o.utputs and the maximum output can be up to $140 \mathrm{~mW}$. Vibrations of bridges, vehicle suspensions, tall buildings etc., can be the source of excitations with low frequency. E.I Sayed et al.[1] have presented an electromagnetic, electrostatic and piezoelectric energy harvesting mechanisms and pointed out that vibrations are a key to drive all energy harvesters. It was shown that adjusting electrical configuration of the coils can maximize power output. Slim Naifare et al.[2] have carried out survey particularly on electromagnetic and magneto-electric harvesters for low frequency excitations since several applications have common excitations characterized by low frequency range (limited to $100 \mathrm{~Hz}$ ). An application spectrum of output power vs. excitation frequency is given, from which it is seen that electromagnetic converters are more suitable for vibration excitations at low frequency range. Halim and Park[3] have proposed a frequency-up converter EH from human body motion. This device can be operated efficiently at any frequencies, meaning its non-resonant behavior. Halim et al.[4] have presented the results of experimental analysis of a hand-shaking motion based $\mathrm{EH}$ to generate power sufficient to operate small and portable devices. Takeya et al.[5] have proposed a linear duel-mass electromagnetic transducer for harvesting energy from bridge vibration. It is shown that such a harvester can deliver more power as compared to single mass harvester and has robustness against uncertainties in bridge vibration and tuning errors. Haroun et al.[6] have presented design, simulation and experimentation of a novel micro-EH based free/impact motion. Experimentation on two different prototypes has been carried out. The harvester shows non-resonant behavior in which output power continuously increases with input frequency and or amplitude. Ooi et al.[7] have discussed a method of changing the value of electrical damping in a vibration cycle to enhance operational bandwidth of a vibration based EH. An excellent discussion of various principles of converting one form of energy to another has been elucidated by Szabo et al. in their paper on magnetic circuit modifications in 
resonant vibration harvesters [8].In few of the above cited research papers, some formulae for electromagnetic damping ratio are given involving the design parameters such as magnetic flux density $\mathrm{B}$, the coil length $\mathrm{L}$ across the magnetic field, number of coil windings $\mathrm{N}$ which are determined by the design of electromagnetic coil-magnet system and may involve errors in the estimation of these parameters.(especially in the assumption of copper coil fill factor). As such, in this study, the values of electrical damping ratio $\zeta_{\mathrm{e}}$ and mechanical damping ratio $\zeta_{\mathrm{m}}$ have been determined using the experimental approach. For this purpose, the theoretical expression for power generated of a typical Vibration based Electromagnetic Harvester (VEH) has been derived and the values of $\zeta_{\mathrm{e}}$ and $\zeta_{\mathrm{m}}$ have been estimated by experimental analysis of VEH using an experimental setup developed for the same.

It is observed that maximum available power from a VEH is influenced considerably by the values of mechanical damping ratio $\zeta \mathrm{m}$, electrical damping ratio $\zeta \mathrm{e}$ and the resistive load RL across the electromagnetic coil terminals.

\section{VIbRATION BASED ELECTROMAGNETIC HARVESTER(VEH)}

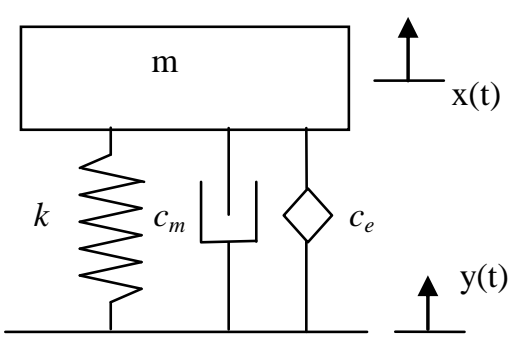

Fig. 1 Schematic of SDOF VEH

In a Vibration based Electromagnetic Harvester (VEH), the conversion of mechanical to electrical energy is based on the Faraday's law $\mathrm{V}=-\mathrm{N} \frac{d \emptyset}{d t}$, where $\mathrm{V}$ is electromotive force, $\mathrm{N}$ is number of coil windings, and $\emptyset_{\text {is }}$ the magnetic flux through single loop. In a VEH, a magnet and coil coupling mechanism is used and under the one direction low frequency excitation from the vibratory source, a relative movement between coil and magnet causes a variation of magnetic flux density giving rise to an e.m.f. through the coil VEH shown in fig. 1 is a SDOF spring (k)-mass (m)-damper (c) system subjected to sinusoidal base excitation $y(t)$.The displacement of harvester mass $(\mathrm{m})$ is $\mathrm{x}(\mathrm{t})$. The relative displacement $z(t)$ between the mass and the base is $x(t)$ $y(t)$. The governing equation of the harvester system is

$$
\mathrm{m} \ddot{z}+\mathrm{cz}+\mathrm{kz}=-\mathrm{m} \ddot{\mathrm{y}}
$$

Where $\mathrm{c}=$ mechanical damping coefficient $\mathrm{c}_{\mathrm{m}}+$ electrical damping coefficient $\mathrm{c}_{\mathrm{e}}$

Considering the base displacement as $y=Y \sin (\omega t)$, where $\omega$ is the circular excitation frequency. The steady state amplitude $\mathrm{Z}$ of the relative displacement will be

$|Z|=\frac{\mathrm{m} \omega^{2} \mathrm{Y}}{\sqrt{\left(\mathrm{k}-\mathrm{m} \omega^{2}\right)^{2}+(\mathrm{c} \omega)^{2}}}$

Using $\zeta_{\mathrm{m}}=\frac{\mathrm{c}}{2 \sqrt{\mathrm{mk}}}, \zeta_{\mathrm{e}}=\frac{\mathrm{c}_{\mathrm{e}}}{2 \sqrt{\mathrm{mk}}}, \omega_{\mathrm{n}}=\sqrt{\frac{\mathrm{k}}{\mathrm{m}}}$ in equation (2) we get,

$$
|Z|=\frac{\left(\frac{\omega}{\omega_{n}}\right)^{2} Y}{\sqrt{\left(1-\left(\frac{\omega}{\omega_{n}}\right)^{2}\right)^{2}+\left(2\left(\zeta_{e}+\zeta_{m}\right)\left(\frac{\omega}{\omega_{n}}\right)\right)^{2}}}
$$

The velocity $(\dot{Z})$ is obtained by the first derivative of the $|\mathrm{Z}|$ of equ. (3) as

$$
\dot{\mathrm{Z}}=\frac{\omega \cdot\left(\frac{\omega}{\omega_{\mathrm{n}}}\right)^{2} \mathrm{Y}}{\sqrt{\left(1-\left(\frac{\omega}{\omega_{\mathrm{n}}}\right)^{2}\right)^{2}+\left(2\left(\zeta_{\mathrm{e}}+\zeta_{\mathrm{m}}\right) \frac{\omega}{\omega_{\mathrm{n}}}\right)^{2}}}
$$

Average Power ( $\left.\mathbf{P}_{\text {ave }}\right)$ (Willam, Yates [9], Roundy [10])

$$
\mathrm{P}_{\mathrm{ave}}=\frac{1}{2} \mathrm{c}_{\mathrm{e}} \dot{\mathrm{z}}^{2}
$$

Using the equation (4) in equation (5), $\mathrm{P}_{\text {ave }}$ is given as

$$
\mathrm{P}_{\mathrm{ave}}=\frac{\mathrm{m} \omega^{3} \mathrm{Y}^{2} \zeta_{\mathrm{e}}\left(\frac{\omega}{\omega_{\mathrm{n}}}\right)^{3}}{\left(1-\left(\frac{\omega}{\omega_{\mathrm{n}}}\right)^{2}\right)^{2}+\left(2\left(\zeta_{\mathrm{e}}+\zeta_{\mathrm{m}}\right) \frac{\omega}{\omega_{\mathrm{n}}}\right)^{2}}
$$

The non-dimensional form of $\mathrm{P}_{\text {ave }}$ is obtained as

$$
\mathrm{P}_{\mathrm{aven}}=\frac{\mathrm{P}_{\mathrm{ave}}}{\mathrm{m} \omega^{3} \mathrm{Y}^{2}}=\frac{\zeta_{\mathrm{e}}\left(\frac{\omega}{\omega_{\mathrm{n}}}\right)^{3}}{\left(1-\left(\frac{\omega}{\omega_{\mathrm{n}}}\right)^{2}\right)^{2}+\left(2\left(\zeta_{\mathrm{e}}+\zeta_{\mathrm{m}}\right) \frac{\omega}{\omega_{\mathrm{n}}}\right)^{2}}
$$

The maximum value of $\mathrm{P}_{\text {aven }}$ is obtained at resonance when $\zeta_{\mathrm{m}}=\zeta_{\mathrm{e}}$

\section{EFFECT OF ELECTRICAL ( $\left.\zeta_{e}\right)$ AND MECHANICAL DAMPING RATIOS AND $\left(\zeta_{m}\right)$ ON $\mathbf{P}_{\text {AVEN }}$}

\section{A. Effect of variation of electrical damping ratio $\zeta_{e}$ on $\mathbf{P}_{\text {aven }}$}

Using equation (7), first of all, the effect of variation of electrical damping ratio $\zeta_{\mathrm{e}}$ on $\mathrm{P}_{\text {aven }}$ is obtained. Figures (2), (3) and (4) show the plots of $\mathrm{P}_{\text {aven }} \mathrm{vs}$. $\zeta_{\mathrm{e}}$ respectively for the values of $\zeta_{\mathrm{m}}=0.0046, \zeta_{\mathrm{m}}=0.046$, (refer section VI-A) and $\zeta_{\mathrm{m}}=0.46$ when $\frac{\omega}{\omega_{\mathrm{n}}}=1$.

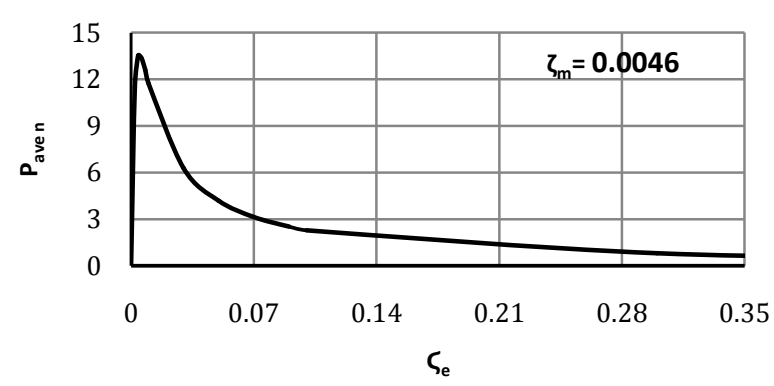

Fig. $2 \mathrm{P}_{\text {aven }}$ Vs. $\zeta \mathrm{e}$ 


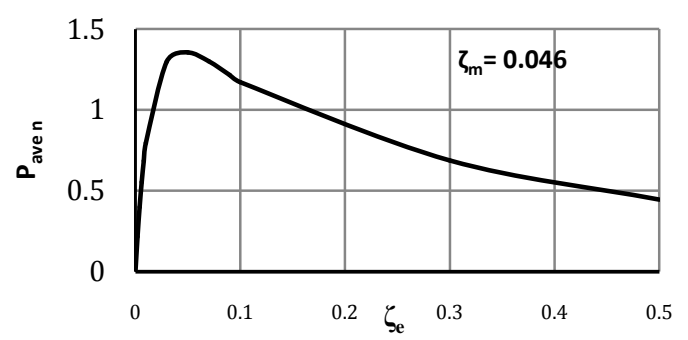

Fig. $3 \mathrm{P}_{\text {aven }}$ vs.לe

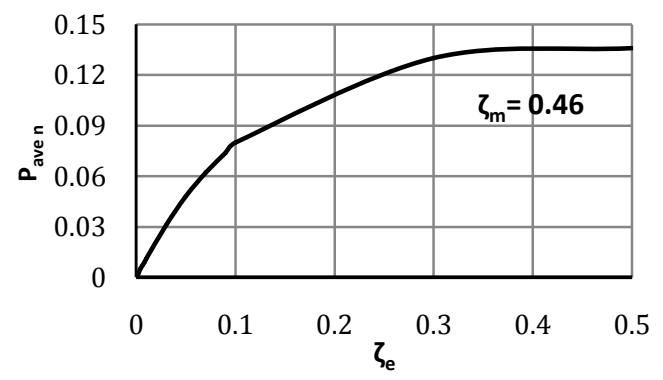

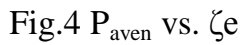

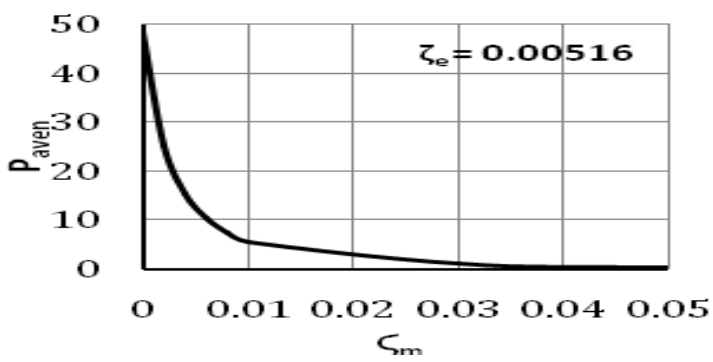

Fig. $5 \mathrm{P}_{\text {aven }}$ vs. $\zeta \mathrm{m}$

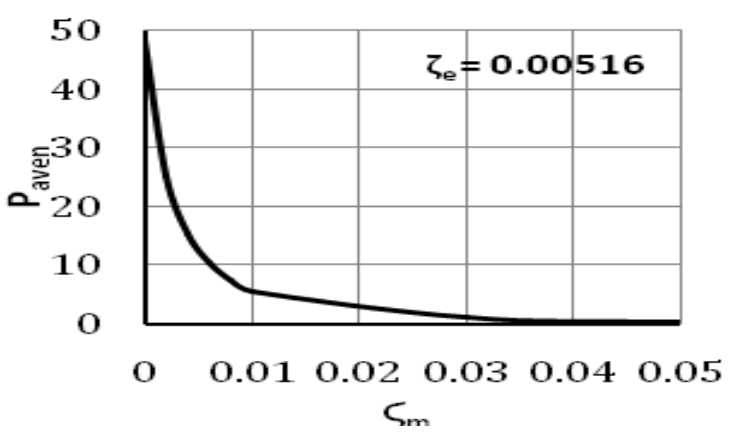

Fig.6 $\mathrm{P}_{\text {aven }}$ vs. לm

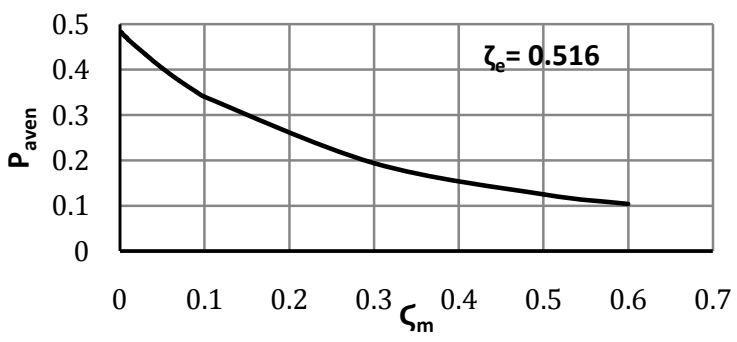

Fig.7 $\mathrm{P}_{\text {aven }}$ vs.לm

B. Effect of variation of Mechanical damping ratio $\zeta_{\mathbf{m}}$ Using equation (7), the effect of variation of mechanical damping ratio $\zeta_{\mathrm{m}}$ on $\mathrm{P}_{\text {aven }}$ is obtained. Figures (5), (6) and (7) show the plots of $\mathrm{P}_{\text {aven }}$ vs. $\zeta_{\mathrm{m}}$ respectively for the values of $\zeta_{\mathrm{e}}=0.00516, \zeta_{\mathrm{e}}=0.0516$, (refer section VI- B) and $\zeta_{\mathrm{e}}=$ 0.516 when $\frac{\omega}{\omega_{\mathrm{n}}}=1$.

\section{DISCUSSION ON RESULTS}

From figures 2,3 and 4 , it is seen that the values of maximum average power obtained are 13.7, 1.375 and 0.137 respectively for $\zeta_{\mathrm{m}}=0.0046, \zeta_{\mathrm{m}}=0.046$ and $\zeta_{\mathrm{m}}=0.46$, when $\frac{\omega}{\omega_{\mathrm{n}}}=1$. From figures 5,6 and 7 , it is seen that the values of maximum average power obtained are $48,4.8$ and 0.484 respectively for $\zeta_{\mathrm{e}}=0.00516, \zeta_{\mathrm{e}}=0.0516$ and $\zeta_{\mathrm{e}}=0.516$, when $\frac{\omega}{\omega_{\mathrm{n}}}=1$. From these results, it is observed that to obtain maximum average power from $\mathrm{VEH}$, it is necessary to keep the mechanical damping ratio $\zeta \mathrm{m}$ as small as possible. The lower values of electrical damping ratio give high values of average power extracted from VEH.

\section{EXPERIMENTAL ANALYSIS}

On the basis of the schematic of a typical VEH is shown in fig.1, an electromagnetic harvester is developed as shown in figure 8. (With coil-magnet system)

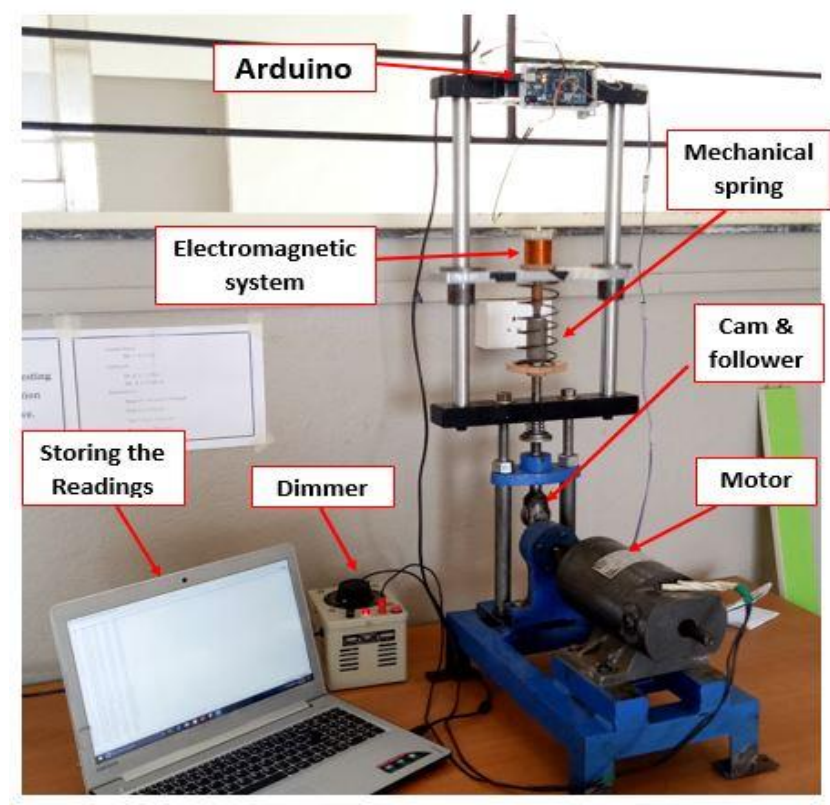

Fig.8 Overall Experimental Setup

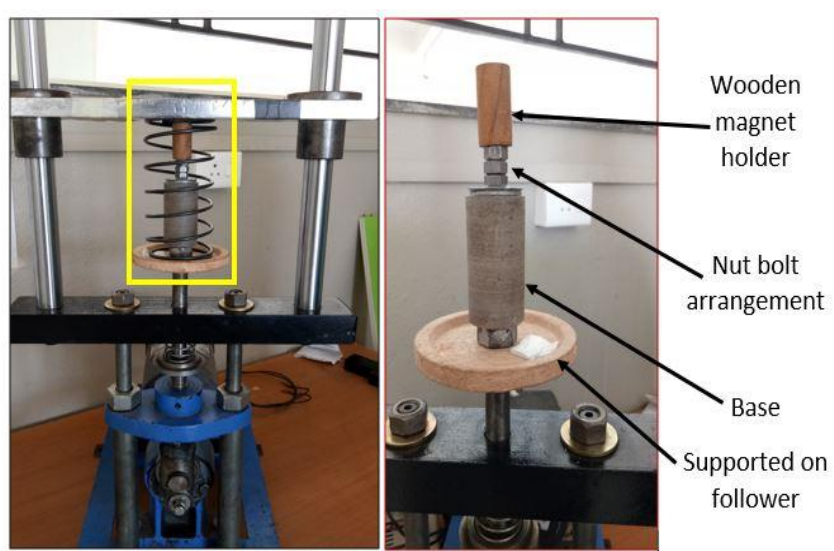

Fig.10 Magnet Holding Device 


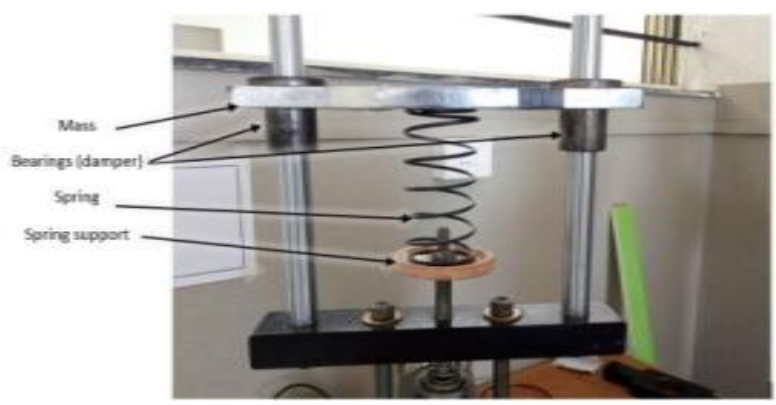

Fig.9 Spring-Mass System

Figure 9 shows the mechanical sub-system (mass-spring) of the harvester. In fig. 10 shows a magnet holding device. The spring mass system of fig. 9 is subjected to a low cycle vibration excitation. For this purpose, a suitable cam follower system is developed to provide $1 \mathrm{~mm}$ steady state amplitude(Y) of excitation at variable angular excitation frequency $(\omega)$. The electrical sub-system of the harvester comprises of a coil and magnet with uni-directional relative movement. A copper coil with inner dia. $20 \mathrm{~mm}$, outer dia. $38 \mathrm{~mm}$, length $40 \mathrm{~mm}$, with 8000 number of turns is developed and the magnet with cylindrical configuration (dia.10mm, length $40 \mathrm{~mm}$ ) of $\mathrm{NdFeB}$.

Some practical limitations in the design of electromagnetic sub-system of VEH (coil and magnet system) are in the manufacturing of the coil, selection of magnet and an estimation of transduction factor

\section{EXPERIMENTAL PROCEDURE}

\section{A. Determination of mechanical damping $\zeta_{\mathrm{m}}$}

Using the setup in fig. 8, the frequency response of the mechanical sub system is obtained using ultrasonic sensor for the measurement of the relative displacement $(\mathrm{z})$ of mass (m) and base at various values of angular excitation frequency $(\omega)$ in the range of 0 to $21.0 \mathrm{rad} / \mathrm{sec}$. The fig. 11 shows the curve of $\mathrm{z}$ vs. $\omega$, from which the mechanical damping ratio $\zeta \mathrm{m}$ of the harvester is obtained by using the half power point method the value of the $\zeta \mathrm{m}$ is calculated as 0.046

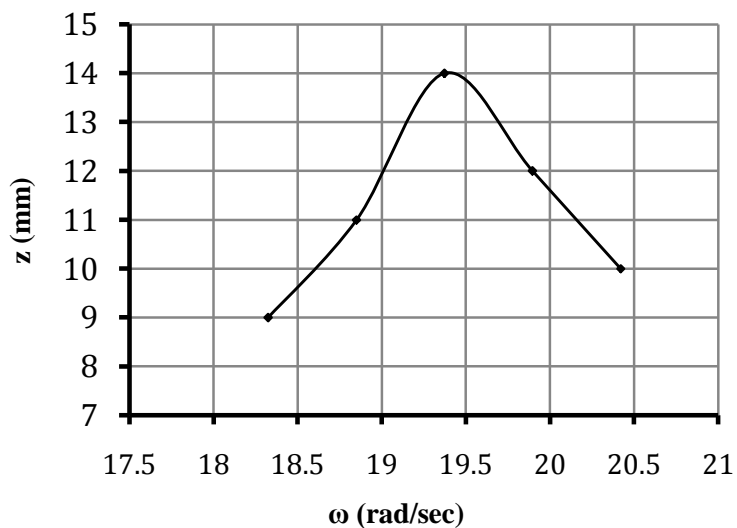

Fig. $11 \mathrm{z}$ vs. $\omega$

\section{B. Determination of open circuit voltage $\mathbf{E}$}

Fig.12 shows the curve of open circuit voltage (E) vs. excitation frequency $(\omega)$.

Using the same procedure the frequency response of the system with magnet-coil combination is obtained and is shown in fig. 13, from which electrical damping ration $\zeta$ e is obtained as 0.0516

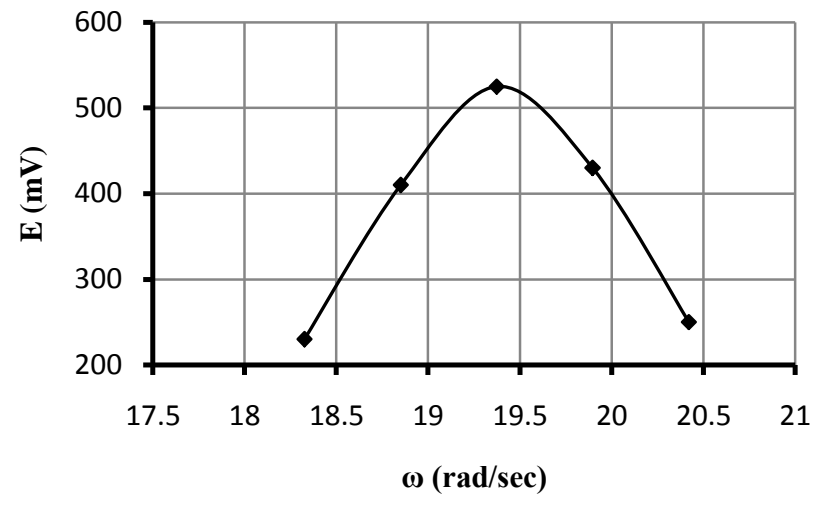

Fig. 12 E vs. $\omega$

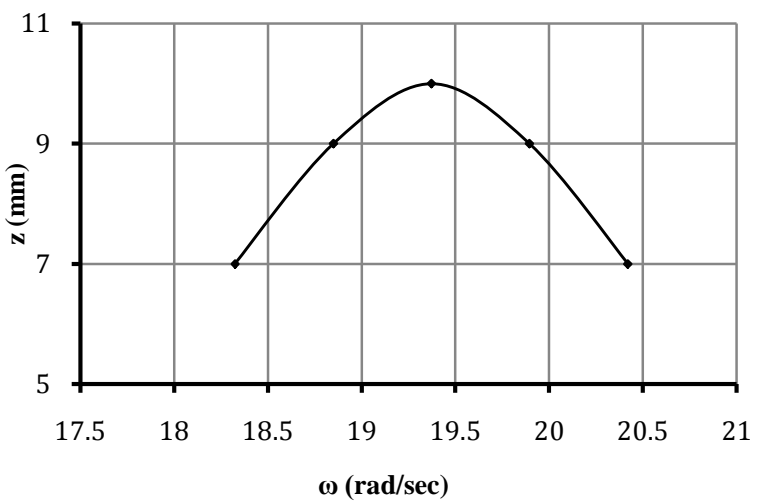

Fig. $13 \mathrm{z}$ vs. $\omega$

C. Voltage $V$ generated across the resistive $\operatorname{load} R_{L}$ and harvested power $P$

To study the effect of the resistive load RL, connected across coil terminals, on the power $\mathrm{P}$ available from $\mathrm{EH}$, using the experimental setup and instrumentation the curves of voltage $\mathrm{V}$ across resistance $R_{L}$ vs. excitation frequency $\omega$, relative displacement z vs. $\omega$ and power P vs. $\omega$ have been obtained for $R_{L}=750 \Omega, R_{L}=1000 \Omega, R_{L}=1287 \Omega, R_{L}=1500 \Omega$ and $R_{L}$ $=1750 \Omega$. In all cases, $\omega_{\mathrm{n}}=19.373 \mathrm{rad} / \mathrm{sec}$ and $\mathrm{Y}$ $=1 \mathrm{~mm}$. Power $\mathrm{P}$ is calculated by the formula $\mathrm{V}^{2} / \mathrm{R}_{\mathrm{L}}$ As a sample example, the curves of $\mathrm{V}$ vs. $\omega, \mathrm{Z}$ vs $\omega$ and $\mathrm{P}$ vs. $\omega$ for the case $R_{L}=1500$ have been shown in figs 14,15 and 16

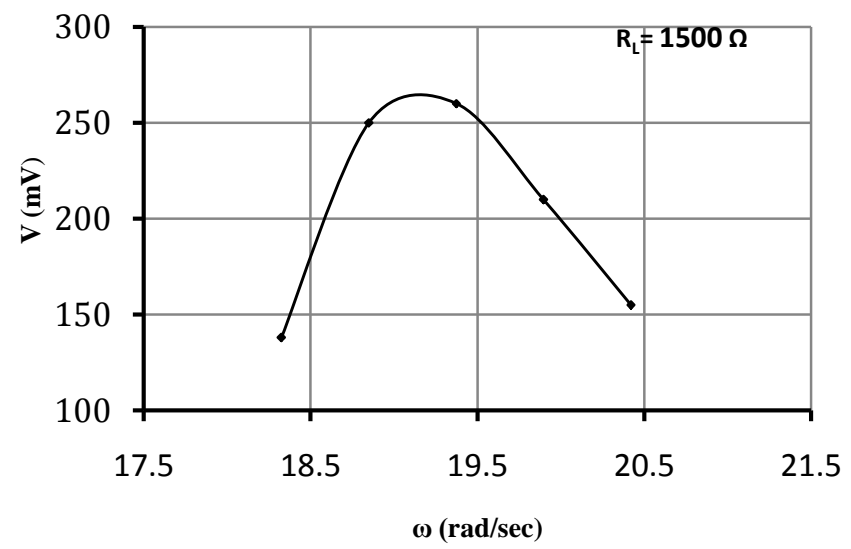

Fig. $14 \mathrm{~V}$ vs. $\omega$ 


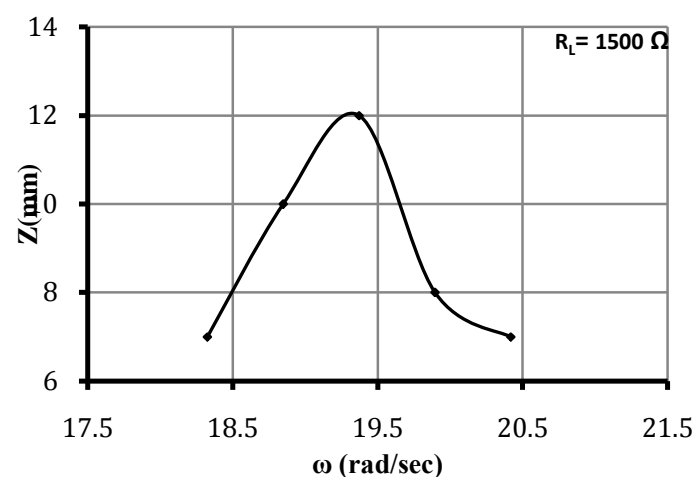

Fig. $15 \mathrm{Z}$ vs $\omega$

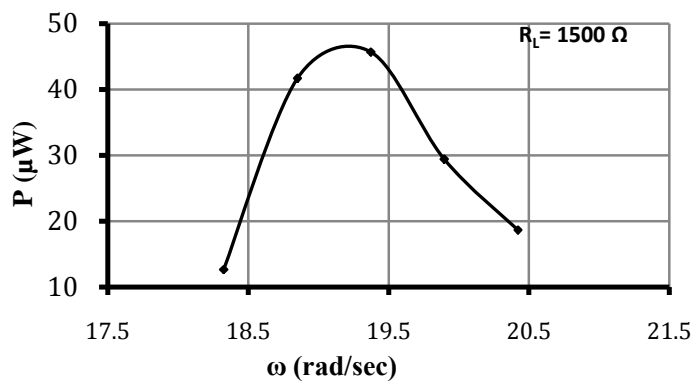

Fig. 16 P vs. $\omega$

Using the same procedure, the curves of V vs. $\omega, \mathrm{Z}$ vs. $\omega$ and P vs. $\omega$ for $R_{L}=750 \Omega, R_{L}=1000 \Omega, R_{L}=1287 \Omega$, and $R L=$ $1750 \Omega$ have been obtained. The values of maximum power, for each value of $\mathrm{RL}$, are obtained and are plotted in fig.17.Also the values of electrical damping ratio $\zeta_{\mathrm{e}}$, for each value of RL are obtained. The curves of $\zeta$ ev (obtained from fig.14.) vs. $\mathrm{R}_{\mathrm{L}}$ and $\zeta_{\mathrm{ez}}$ (obtained from fig 15) vs. $\omega$ are plotted in fig. 18 .

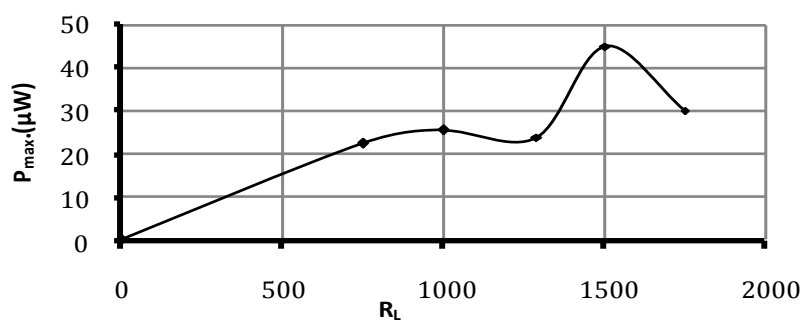

Fig. 17 Pmax vs. $\mathrm{R}_{\mathrm{L}}$

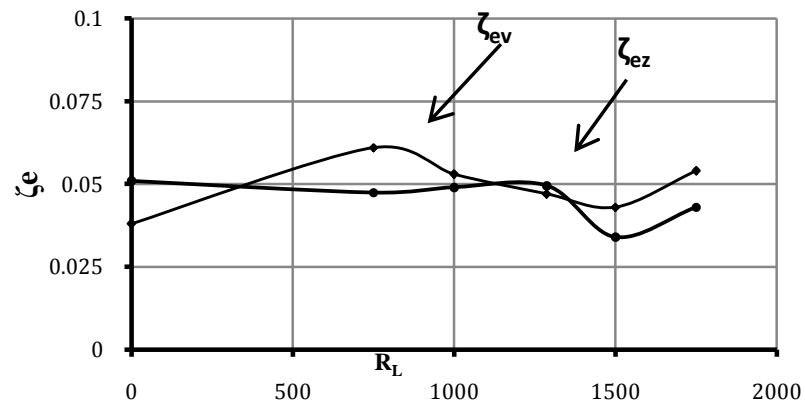

Fig. $18 \zeta_{\mathrm{e}}$ vs. $\mathrm{R}_{\mathrm{L}}$

\section{DISCUSSION ON RESULTS}

From fig.16, it can be seen that the maximum power available from developed Vibration based Electromagnetic Harvester (VEH) is $45.1 \mu \mathrm{W}$ at resonance. It is seen that considerable power is also available in the neighborhood of resonance i. e. at off-resonance conditions.

The corresponding values of available power, at resonance for resistive loads $R_{L}=1000 \Omega, R_{L}=1287 \Omega$, and $R_{L}=1750 \Omega$ are respectively $25.6 \mu \mathrm{W}, 23.8 \mu \mathrm{W}$ and $30.6 \mu \mathrm{W}$. These results show that the resistive load affects considerably the available power from VEH. It is seen that the electrical damping ratio is influenced by the value of resistive load across the electromagnetic coil terminals.

\section{CONCLUSION}

The results of theoretical and experimental analysis of the developed VEH show that the maximum available power from a VEH is influenced considerably by the values of mechanical damping ratio $\zeta \mathrm{m}$, both at resonance and off-resonance conditions, electrical damping ratio $\zeta$ e and the resistive load $\mathrm{R}_{\mathrm{L}}$ across the electromagnetic coil terminals. The $\zeta \mathrm{m}$ should be as small as possible and $\zeta \mathrm{e}$ should be nearly equal to $\zeta \mathrm{m}$ for maximum power generation from VEH.

\section{REFERENCES}

1. Abdul-Rahman El-Sayed Kelvin Tai and Mohammad Biglarbegian Shohel Mahmud, "A Survey on Recent Energy Harvesting Mechanisms", IEEE Canadian Conference on Electrical and Computer Engineering, (2016)

2. Slim Naifar,Sonia Bradai,ChristianViehweger,Olfa kanoun, "Survey of Electromagnetic and Magnetoelectric Vibration Energy Harvester for Low Frequency Excitation", Measurement, volume 106, 2017, pp.251-262.

3. Miah A,Halim,JaeY,Park, "Modelling and experiment of a handy motion driven, frequency up-converting electromagnetic energy harvester using transverse impact by spherical ball", Sensors and actuators, volume 229,2015, pp.50-58.

4. Miah A,Halim,Hyunok Cho,JaeY,Park, "Design and experiment of human-limb driven, frequency up-converted electromagnetic energy harvester", Energy conversion and management 106,2015, pp.393-404

5. Kouichi Takeya , Eiichi Sasaki, Yusuke Kobayashi, " Design and parametric study on energy harvesting from bridge vibration using tuned dual-mass damper systems", Journal of Sound and Vibration 361,2016,pp. 50-65.

6. Ahmed Haroun, IchiroYamada,Shinichi Warisawa, "Micro Electromagnetic Vibration Energy Harvester Based on free/Impact Motion for Low Frequency- Large Amplitude Operation", Volume 224, 2015, pp. 87-98.

7. Ahmed Haroun, IchiroYamada,Shinichi Warisawa, "Micro Electromagnetic Vibration Energy Harvester Based on free/Impact Motion for Low Frequency- Large Amplitude Operation", Volume 224, 2015, pp. 87-98.

8. Zoltan Szabo,Pavel Fiala, Premysl Dohnal, "Magnetic circuit modification in resonant vibration harvesters",Mechanical system and signal processing,2018,pp.832-845.

9. Williams, C. B. and Yates, R. B., "Analysis of a micro-electric generator for microsystems.", Sens. Actuators A, 1996,52,pp. 8-11

10. S.Roundy, P.K. Wright, J. Rabaey, "A study of low level vibrations as a power source wireless sensor nodes", Computer Communications 26, 2003),pp.1131-1144.

11. Dirk Spreemann, Yiannos Manoli, "Electromagnetic Vibration Energy Harvesting Devices.", Springer series in advanced microelectrcronic 35,2012 


\section{AUTHORS PROFILE}

Vijay B. Patil, working as Assistant Professor in Department of Mechanical Engineering at Annasaheb Dange College of Engineering and Technology, Ashta,Sangli, Maharashtra, He has obtained his graduation in Mechanical Engineering in the year 1995 and post graduate degree in Design Engineering from Rajarambapu Institute of Technology sakharale, Sangli Maharashtra in the year 2005. He is Ph.D. research scholar at BLDEA's Vachana Pitamaha Dr. P.G. Halakatti College of Engineering and Technology, Vijayapur, Karnataka State affiliated to Visvesvaraya Technological University, Belgavi, Karnataka state. He has twenty years of teaching and two years of industrial experience. His areas of interest are, Energy Harvesting, Sound and Vibration, Finite Element Analysis.

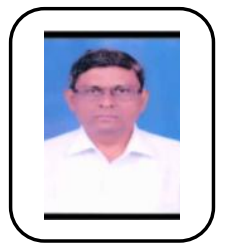

Dr. Mahadev I. Sakri, working as Professor and Head of Automobile Engineering at BLDEA's Vachana Pitamaha Dr. P.G. Halakatti College of Engineering and Technology, Vijayapur, Karnataka State. He has obtained his post graduate degree (Design of Mechanical Equipment) from Indian Institute of Technology-Delhi in the year 1995. In the year 2009, Anna University, awarded him doctoral degree for his thesis entitled, "Experimental Investigations on Electronic Packages Subjected to Dynamic Loads". He has thirty years of teaching and ten years of research experience. His areas of interest are, Composite Materials, Sound and Vibration. He has more than 40 conference and journal publications to his credit. $\mathrm{He}$ is guiding five research candidates. $\mathrm{He}$ has been honored twice with best paper award for his publications made in international conferences. $\mathrm{He}$ has fetched rupees twenty lac research grant from government of Karnataka in the year 2015 . 